Jurnal

Kardiologi Indonesia

J Kardiol Indones. 2013;34:20-2

ISSN 0I 26/3773

\title{
Circulating Endothelial Progenitor Cells is a predictor in Atherosclerosis: Is it really a promising candle?
}

Anwar Santoso

Circulating endothelial progenitor cells (CEPC) are supposed to be a subset of bone marrow-derived peripheral blood mononuclear cells (PBMC), revealing immature surface markers common to hematopoietic stem cells, such as CD 34 and CD 133 and endothelial lineage markers. These cells can be isolated from peripheral, umbilical cord, and bone marrow blood. CD 34 represents a marker of immature stem cells that is commonly used to characterize CEPC together with other surface antigens. Though, as CD 34 is also expressed at lower levels on mature endothelial cells, most recent studies used CD 133, a marker of more immature hematopoietic stem cells that is now considered the best surface marker to define, identify and isolate the CEPC ${ }^{1}$. CD 133 (also known as AC 133 or prominin) is highly conserved antigen with unknown biological activity. It would be expressed on hematopoietic stem cells, but not on mature endothelial cell and monocytes. In order to reflect the endothelial cells, there is general agreement for the use of at least one additional marker, such as vascular endothelial growth factor receptor-2 (VEGFR-2 or KDR), while others are platelet-endothelial cells adhesion molecules-1 (PECAM-1), von Willebrand factor, c-kit, Tie-2, vascular endothelial-cadherin and VEGFR-12.

\footnotetext{
Alamat Korespondensi:

Anwar Santoso, MD, Dept. of Cardiology-Vascular Medicine, School of Medicine - University of Indonesia, National Cardiovascular Centre, Harapan Kita Hospital, Jakarta. E-mail: awscip@gmail.com
}

The pivotal role shown by the endothelial cells in cardiovascular (CV) biology has been becoming increasingly appreciated. Endothelial injury has been involved in atherosclerosis, thrombosis, and hypertension, and the balance between endothelial injury and endothelial recovery is of supreme importance for reducing CV events. Further, other studies are also providing intriguing and encouraging insight into the potential use of CEPC in the clinical setting.Indeed, there is accumulating evidence for reduced availabilityand impaired CEPC function in the presence of both CV disease and associated comorbid risk factors ${ }^{3}$ with endothelial dysfunction.

Endothelial dysfunction, detected as the presence of reduced vasodilating response to endothelial stimuli, has been observed to be associated with major CV risk factors, such as aging, diabetes, hypercholesterolemia, hypertension, smoking, hyperhomocysteinemia, and postmenopause state ${ }^{4,5}$. Accordingly, endothelial function is proved to be associated with the number of CV risk factors and therefore with the global CV risk. This was also confirmed in the Framingham population, in which an escalating inverse relationship between endothelial-dependent relaxation, estimated by flowmediated dilatation (FMD) and the CV risk score.

Multiple studies have consistently reported an association between lipid metabolism and the biology ofhuman EPC. The numbers of EPC colony forming unitsare significantly reduced in relatively healthy subjects with hypercholesterolemia ${ }^{5}$. In CAD, 
low-densitylipoprotein (LDL) cholesterol inversely correlates with the number of CEPC. In addition, the functional characteristics of isolated EPC, such as proliferation, migration, adhesion, and in vitro vasculogenic capacity, are also impaired in patients with hypercholesterolemia ${ }^{5}$.

Among several CV risk factors, hypertension is the strongest predictor of CEPC migratory impairment. Angiotensin II reduces telomerase activity in CEPC and accelerates the onset of CEPC senescence via an enhanced oxidative stress ${ }^{6}$. Although angiotensin II inhibited CEPC proliferation in one study, but it increase VEGF-induced EPC proliferation in another. Angiotensin II also potentiates VEGF-induced network formation by CEPC, maybe by upregulation of KDR. Angiotensin II likely would induce increased shear stress, and subsequently it increases differentiation, adhesion, migration, proliferation, antiapoptosis, and vasculogenesis of CEPC by activation of VEGFR-2 and signal transduction pathway ${ }^{7}$.

Diabetes mellitus, another important $\mathrm{CV}$ risk factor, is a disease in which impairment of ischemiainduced neovascularization has been described. The number of CEPC is reduced in diabetes ${ }^{1}$. Furthermore, marked CEPC dysfunction may underlie new mechanisms involved in the pathogenesis of vascular complications in diabetic patients ${ }^{1}$. Diminished CEPC supplied by diabetes may be ascribed to impaired CEPC production in bone marrow and to decreased CEPC mobilization from spleen, which may contribute to endothelial dysfunction in diabetes ${ }^{8}$. Further evidence of the adverse impact of hyperglycemiaon CEPC was shown by Kränkel et al. ${ }^{9}$, who demonstrated that cultivation of PBMNC from healthy donors under hyperglycemic conditionswas associated with significant reduction in CEPC numbers, inhibition of $\mathrm{NO}$ production, and matrixmetalloproteinase-9 activity, as well as an impairment of them igrational and integrative capacities of the cells.

In order to prove the reality in our own population in Indonesia, one of the investigators recently had conducted the study and published in this journal. They recruited 55 subjects (normal subjects, those with CVD risk and CVD subjects) and divided them into 6 groups, based on "Framingham risk score'. CEPC was measured by flow cytometry, and confirmed using CD 34 Per CP Santa Cruz SC-19621 and CD 133 FITC (fluorescein isothiocyanate) Bioss bs-0395R-FITC. Further, to indicate circulating endothelial cells (CEC), they were measured using CD45 FITC Biolegend
202205 and CD 146 PE Biolegend 134704 marker.

Unpredictably, the study suggested that: increased EPC was associated with increased CVD risk based on the Framingham risk score'. This finding unfortunately did not confirm the previous available studies. This might be explained by such following: "CEPC count in vitro does not provide information on the absolute number of CEPC $^{10}$, because they depend not only on the initial number of progenitors, but also on adhesion, proliferation and survival of plated EPC, resulting from complex in vivo cellular interactions. These considerations suggest that it may be difficult to define the "true" population of CEPC and reflects in vivo setting ${ }^{2}$. Anyway, we appreciated with this initiative to conduct the study, as the proverb says: better to light a candle than to curse the darkness.'

\section{References}

1. Fadini GP, Agostini C, Avogaro A. Endothelial Progenitor Cells and Vascular Biology in Diabetes Mellitus: Current Knowledge and Future Perspective. Curr Diabetes Review 2005;1:41 58.

2. Urbich C, Dimmeler S. Endothelial progenitor cells: characterization and role in vascular biology. Circ Res 2004;95(4): 343-53.

3. Shantsila E, Watson T, Lip GYH. Endothelial Progenitor Cells in Cardiovascular Disorders. J Am Coll Cardiol 2007;49(7): 741-52.

4. Brunner H, Cockcroft JR, Deanfield J, et al. Endothelial function and dysfunction. Part II: Association with cardiovascular risk factors and diseases: a statement by the Working Group on Endothelins and Endothelial Factors of the European Society of Hypertension. J Hypertens 2005;23:233-46.

5. Chen JZ, Zhang FR, Tao QM, et al. Number andactivity of endothelial progenitor cells from peripheral blood inpatients with hypercholesterolaemia. Clin Sci (Lond) 2004;107:27380.

6. Imanishi T, Hano T, Nishio I. Angiotensin II potentiates vascularendothelial growth factor-induced proliferation and network formationof endothelial progenitor cells. Hypertens Res 2004;27:101- 8.

7. Obi S, Masuda H, Shizuno T, et al. Fluid shear stress induces differentiation of circulating phenotype progenitor cells. Am J Physiol Cell Physiol 2012;303:C595-C606.

8. Saito H, Yamamoto Y, Yamamoto H. Diabetes alters subsets of endothelial cells that reside in blood, bone marrow, and spleen. Am J Physiol Cell Physiol 2012;302:C892-C901.

9. Krankel N, Adams V, Linke A, et al. Hyperglycemia reduces 


\section{Jurnal Kardiologi Indonesia}

survivaland impairs function of circulating blood-derived progenitor cells.Arterioscler Thromb Vasc Biol 2005;25:698 -703 .

10. Nurwidyaningtyas W, Sargowo D, Agoes A, Andri TW, Satu- man. J Kardiol Indones. 2013;34:14-9.

11. Rabelink TJ, de Boer HC, de Koning EJ, et al. Endothelial progenitor cells: more than an inflammatory response? Arterioscler Thromb Vasc Biol 2004;24(5):834-8. 